\title{
Da impotência à disfunção erétil. Destinos da medicalização da sexualidade
}

\author{
| 'Alain Giami | \\ | Tradução: ${ }^{2}$ Keyla Cristiane do Nascimento | \\ | Revisão Técnica: ${ }^{3} J a n e$ Russo |
}

Resumo: Este artigo retrata a história recente da transformação do conceito da impotência, como desordem psicossexual, em disfunção erétil, considerada como uma doença de etiologia principalmente orgânica. Demonstra sucessivamente como a impotência masculina constituiu uma abrangência global de todo o ciclo da resposta sexual, e ainda, uma violação da identidade e da autoimagem; como o relacionamento entre casais se transformou progressivamente em dificuldade e como a falta de um órgão claramente circunscrito pode ser o objeto de um "simples" tratamento medicamentoso. Este processo foi analisado a partir de modelo sequencial da medicalização (Conrad), que permite compreender a intervenção dos diferentes atores envolvidos (cientistas, médicos, industriais, políticos, empresários). Compreende-se, assim, como as descobertas científicas são selecionadas e desenvolvidas de acordo com seu potencial industrial e são aplicadas às pesquisas clínicas; como entidades clínicas são reconceitualizadas e medidas através de investigações epidemiológicas na população em geral e como são criados os ensaios clínicos que levam à criação de um medicamento. Em seguida, observam-se como os atores da saúde pública e os políticos intervêm para dar legitimidade ao novo problema criado. Por fim, avalia-se a possibilidade da desmedicalização de problemas com o uso não-médico do medicamento, no contexto do desenvolvimento da autoprescrição na Internet.

\footnotetext{
Palavras-chave: medicalização; disfunção erétil; sexualidade.
}

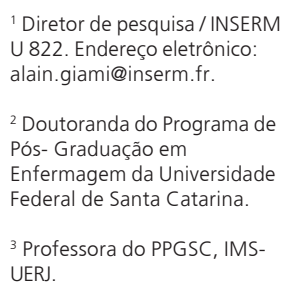

1 Diretor de pesquisa / INSERM U 822. Endereço eletrônico: alain.giami@inserm.fr.

2 Doutoranda do Programa de Pós- Graduação em Enfermagem da Universidade Federal de Santa Catarina.

3 Professora do PPGSC, IMSUERJ.

Recebido em: 05/11/2008 Aprovado em: 13/07/2009 
A medicalização foi imposta às sociedades ocidentais a partir do século XIX, como uma das principais características do discurso e da prática sobre a sexualidade. Pode-se dizer que o próprio termo sexualidade, inventado em meados do século XIX, foi inscrito imediatamente no registro da medicalização (FOUCAULT, 1976; FASSIN, 1998; GIAMI, 2005). A impotência masculina e seus diferentes tratamentos representam um dos exemplos mais ilustrativos desse processo de medicalização. Este artigo trata das formas recentes da medicalização da impotência masculina (TIEFER, 1996; GIAMI, 2000a) que se desenvolveram desde o início dos anos 80. Colocam-se em evidência o papel e a influência de diferentes agentes e instituições - médicos e não-médicos - comprometidos com o desenvolvimento do processo de medicalização da impotência masculina. Esse processo foi analisado utilizando-se o "modelo sequencial da medicalização" de P. Conrad e J. Schneider (CONRAD; SCHNEIDER, 2007; CONRAD, 2007).

Esse processo não é redutível ao campo da medicina, na medida em que agentes e instituições não-médicas estão presentes juntamente com agentes médicos, e suas consequências ultrapassam o campo da medicina. Neste artigo, tentou-se articular a lógica de uma construção social da impotência masculina baseada nas intervenções de diferentes agentes e instituições com progressos sequenciais que aparecem ordenados segundo uma cronologia. Além disso, a análise desse processo coloca em evidência como a construção da nova entidade clínica designada "disfunção erétil" foi associada, em certo momento, ao desenvolvimento e à comercialização de uma nova classe de drogas - os inibidores da fosfodiesterase dentre as quais o Viagra (citrato de sildenafil) constitui, ainda, o exemplo mais conhecido, dez anos após sua colocação no mercado, em 1998. Objetiva também destacar as implicações desses conceitos e práticas, no que diz respeito às normas sociais acerca da sexualidade. Finalmente, discutir-se-á como o processo de medicalização da impotência masculina contém as possibilidades de sua desmedicalização. As primeiras fases do processo situam-se no nível internacional, principalmente norte-americano, onde a investigação médico-científica sobre a sexualidade é a mais desenvolvida do mundo ocidental. Dadas as diferenças entre os sistemas nacionais de saúde, fases de institucionalização e de legitimação da impotência masculina, as questôes específicas de saúde pública serão analisadas a partir da situação francesa. ${ }^{1}$ 


\section{A pré-história da medicalização da impotência masculina}

A história das ideias sobre a impotência masculina torna muito evidente que essa condição foi codificada no registro médico desde o advento da antiga medicina e foi retomada mais tarde nos registros religiosos e jurídicos (DARMON, 1979). A partir de meados do século XIX, a impotência masculina é definida como uma categoria médica e é tratada por médicos, venereologistas inclusive, sob a forma de uma "perda da virilidade" e como causa de infertilidade masculina (BELLIOL, 1832; ROUBAUD, 1855; ACTON, 1865), e por psiquiatras sob a categoria geral de "neurastenia sexual" (BEARD, 1884). No início do século XX, a impotência sexual masculina interessou também aos psicanalistas, que propunham dois tipos de explicação: por um lado, uma concepção intrapsíquica baseada na utilização de uma etiologia de trauma infantil e, por outro, a abertura psicossocial de Stekel, levando em conta as parceiras e normas sociais.

\section{O desenvolvimento da sexologia americana}

Os trabalhos de Masters e Johnson se situam entre a psicologização e a medicalização da impotência masculina. Inicialmente, significam o abandono do modelo psicanalítico da impotência. Seus trabalhos fundamentais, efetuados em laboratório, estabeleceram as bases de um modelo psicofisiológico da resposta sexual humana considerada como uma forma de "comportamento natural", que contribui para a comunicação entre o casal e o desenvolvimento conjugal. ${ }^{2}$ Estabeleceram critérios distintivos (impotência primária ou secundária) baseados em medidas objetivas. Desenvolveram também uma teoria da impotência que a coloca explicitamente como incapacidade para realizar o coito heterossexual no contexto de um casal, excluindo outras práticas e situações sexuais. ${ }^{3}$

As principais disfunções do casal são interpretadas como causa e consequência de falhas da função erótica. $\mathrm{Na}$ ausência de tratamento farmacológico eficaz, desenvolveram uma abordagem terapêutica que se inscreve no registro de mudanças comportamentais. A produção fisiológica das ereçôes e o retorno à ereção não constituíam os objetivos imediatos do tratamento, que eram da ordem da aprendizagem e da mudança comportamental. Um discípulo de Masters e Johnson, tomando posição claramente contra os projetos de tratamentos farmacológicos que começavam a surgir naquele momento, afirmava: "O tratamento médico não 
terá como objetivo clínico promover uma ereção. O paciente deve compreender desde o início que o médico não é mais capaz de incitar uma ereção por meio de algum segredo farmacológico" (TRIMMER, 1981, p. 77). A posteriori, essa posição constitui uma declaração ideológica contra as inovações que estavam por vir. Embora as explicações da impotência masculina evoluam cada vez mais para uma abordagem orgânica e fisiológica, os tratamentos mais válidos e mais utilizados permanecem ancorados na área da psicoterapia.

\section{A renovação das descobertas científicas}

Desde o final dos anos 70, determinado número de moléculas para restabelecer a ereção foram testadas (SEAGRAVES, 1998), porém, a maioria desses tratamentos foi considerada pouco eficaz (GARCIA-REBOLL; MULHALL; GOLDSTEIN, 1997). Assim, uma primeira reunião científica sobre a cirurgia de "revascularização peniana" foi organizada em Nova York no ano de 1978 pelo Dr. Adrian Zorgniotti (Cabrini Medical Center). Essa reunião reagrupou os pesquisadores e os médicos que desempenharam papel importante no desenvolvimento das instituições de pesquisas da "medicina sexual": o dinamarquês Gorm Wagner e os americanos Ira Sharlip e Ron Lewis (LEWIS; WAGNER, 2008). As descobertas científicas e técnicas mais marcantes ocorreram no início dos anos 80: descoberta da ação da papaverina em injeção intracavernosa (IIC) por um cardiologista francês (VIRAG, 1982); descoberta da ação do óxido nítrico $(\mathrm{NO} 2)^{4}$ - (FURCHGOTT; IGNARRO, 1987) e sua posterior aplicação no estudo dos processos neurovasculares da ereção (RAJFER et al., 1992).

Os urologistas apoderaram-se destas novas ferramentas para investir de modo mais acentuado no campo da impotência masculina e para redefinir os contornos da pesquisa fundamental e dos tratamentos (KRANE; SIROKY; GOLDSTEIN, 1983). Esses urologistas se comprometeram, por conseguinte, a reconceitualizar a impotência masculina de modo a incluir essa patologia em seu campo de ação e preparar o caminho para novos tratamentos que seriam exibidos ao longo dos anos seguintes. Ao fazê-lo, situaram-se no contexto da evolução da urologia, caracterizada principalmente, até então, como um ramo da cirurgia. A disciplina abriu-se, deste modo, a novos conceitos e práticas, utilizando cada vez mais a endocrinologia e os tratamentos farmacológicos associados à andrologia. Estas novas abordagens urológicas contrastam radicalmente com as abordagens urológicas do século XIX, baseadas na ideia da irritação da uretra. 
A estratégia médico-científica vai-se implantar em torno das seguintes linhas: definição da nosografia, epidemiologia, desenvolvimento de questionários de avaliação e realização de ensaios clínicos dos novos medicamentos.

\section{Nosografia: as dificuldades sexuais localizadas num órgão}

Numa revisão da literatura intitulada "Impotência" (publicada no New England Journal of Medicine em 1989), os urologistas do "grupo de Boston" consideraram que aproximadamente dez milhões de americanos sofrem de impotência. Fundamentam suas argumentações em descobertas técnicas e científicas.

Durante a última década, o principal avanço na compreensão da impotência residiu na observação do estado de contração ou relaxamento da musculatura lisa, que regula o fluxo de sangue no corpo cavernoso e determina o estado de flacidez ou de ereção do pênis. A capacidade de influenciar o estado dos músculos lisos por injeção intracavernosa de agentes farmacológicos levou ao desenvolvimento de novos procedimentos diagnósticos e terapêuticos da impotência. (KRANE; GOLDSTEIN; SAENZ DE TEJADA, 1989, p. 1.656).

Esses novos urologistas propuseram abandonar o termo "impotência" em favor de "disfunção erétil", definida como
a incapacidade persistente de conseguir ou manter uma rigidez suficiente na ereção para ter uma relação sexual. O grau de disfunção erétil é variável e pode se situar entre uma redução parcial da rigidez peniana ou da incapacidade em manter a ereção e uma falta completa de ereção. Esta definição é limitada à capacidade erétil do pênis e não inclui os problemas de libido, distúrbios da ejaculação ou do orgasmo (KRANE et al., 1989).

Esta definição não inclui nenhuma repercussão psicológica relacionada à desordem, o que caracterizava as abordagens anteriores da impotência.

A "gravidade" de impotência é medida através de um conjunto de critérios: diminuição ou perda da rigidez peniana, que pode ser de natureza temporária ou permanente. $\mathrm{O}$ critério de frequência de aparição, estabelecido por Masters e Johnson, é abandonado. A referência ao parceiro como etiologia e como base do tratamento, até então central, também é deixada de lado. Assim, os novos critérios se baseiam tão somente na avaliação do grau de rigidez da ereção e remetem diretamente para novos conceitos científicos que são transpostos para o nível do diagnóstico. 
Novas relações são então estabelecidas entre os avanços científicos, a concepção etiológica fundada sobre a neuroendocrinologia e as recomendaçôes a respeito dos tratamentos existentes e futuros. A principal mudança reside no estabelecimento de uma etiologia orgânica, fundamento dos tratamentos farmacológicos posteriores: as moléculas agem sobre os corpos. A ereção, como processo fisiológico, fica isolada do resto do ciclo de resposta sexual humana e da relação sexual (HSRC) estabelecido por Masters e Johnson. Os conceitos de etiologia psicológica e a dimensão comportamental dos tratamentos são abandonados. Este modelo se inscreve no quadro estereotipado do senso comum sobre a sexualidade masculina, dominado pelas urgências biológicas e pela falta de referência às relações e aos sentimentos que unem os parceiros. Alguns anos mais tarde, quando esse novo modelo organicista foi aplicado para a explicação das disfunçôes sexuais femininas, uma violenta controvérsia científica foi levantada. Pesquisadores feministas recusaram a aplicação de um modelo organicista, excluindo as dimensões relacional e sentimental para a explicação da sexualidade feminina. No caso dos homens, ao contrário, a redução do modelo psicofisiologista de Masters e Johnson a uma simples questão de funcionamento erétil não levantou qualquer questão. ${ }^{5}$

Esse artigo e os seguintes (particularmente os que concernem aos resultados dos ensaios clínicos do Viagra) foram publicados nas revistas médicas mais prestigiadas e não em revistas sobre sexologia - altamente desenvolvidas nos Estados Unidos desde os anos 60 (ZUCKER, 2002), que garantiram a divulgação das teorias psicológicas e dos tratamentos comportamentais. Assim, os urologistas devolveram à impotência sua legitimidade, suprimindo seus componentes psicológicos, além de qualquer referência à totalidade da pessoa e ao relacionamento de casal. Ao mesmo tempo, abriram novos caminhos para a urologia, reduzindo a influência do modelo baseado na intervenção cirúrgica.

\section{Epidemiologia: a política do número}

A epidemiologia dos problemas e dificuldades sexuais já estava bem estabelecida antes da chegada dos urologistas no domínio da impotência. Em 1990, uma revisão crítica da literatura tinha produzido um consenso de que a prevalência da impotência se situa entre 3 e $9 \%$ dos homens adultos (SPECTOR; CAREY, 1990). Entre 1990 e 2001, podíamos observar um desenvolvimento importante de trabalhos epidemiológicos sobre a impotência masculina e as perturbaçôes sexuais 
em geral: mais de 50 pesquisas epidemiológicas (em populaçôes gerais e entre grupos de populações clínicas) foram realizados (SIMONS; CAREY, 2001). Em 1987, Irwin Goldstein e seus associados do "grupo de Boston" realizaram uma investigação epidemiológica na população em geral, financiada por fundos federais, entre os homens de mais de 40 anos: a Massachusetts Male Aging Study (MMAS), cujos primeiros resultados foram publicados numa revista científica de urologia (FELDMAN et al., 1994). Os resultados dessa investigação apontam a existência de "disfunção erétil" em mais de $50 \%$ da população masculina, estabelecendo um aumento considerável da prevalência do distúrbio. A prevalência total foi segmentada em graus de gravidade recolhidos através de um questionário autoaplicável dirigido aos homens: "A impotência moderada constitui a categoria mais representativa com uma prevalência de $25,2 \%$, a que se segue é a impotência mínima com $17,2 \%$ e a mais baixa é a impotência completa com 9,6\%.” (FELDMAN et al., 1994, p. 55).

Essa investigação, embasada numa nova definição de impotência, permite, assim, triplicar a estimativa da prevalência média, tal como era anteriormente reconhecida pelos mesmos urologistas (agora 30 milhões de homens seriam atingidos pelo distúrbio nos Estados Unidos), e estabelecer que os principais fatores de risco para a impotência são de origem orgânica. A MMAS se impôs, nesse momento, como a principal base de referência epidemiológica da grande maioria de publicações desta área (GIAMI, 2000b).

\section{Ensaios e aplicações clínicas}

O desenvolvimento de um tratamento farmacêutico passa necessariamente por toda uma série de ensaios clínicos de diferentes fases para avaliar a tolerância, a toxicidade, a dosagem e a eficácia de uma molécula, dentro de um quadro de indicações específicas. Os ensaios clínicos contribuem para a construção das características do produto e para moldar seu perfil. O sildenafil deve ser construído como um medicamento e não como um afrodisíaco, e seus ensaios irão contribuir para sua definição como tratamento de uma doença específica. Respondendo a uma entrevista do New York Times em fevereiro de 2000, Irwin Goldstein, urologista da Universidade de Boston e principal promotor da "disfunção erétil" e da "medicina sexual", declarava que "na ausência de tratamento, não há nenhuma doença” (HITT, 2000). 
A tolerância e a eficácia do sildenafil foram destacadas em 1996 (BOOLELL et al., 1996) por uma equipe de pesquisadores da empresa globalizada Pfizer (Pfizer Central Research, Sandwich, Reino-Unido). Esses ensaios, dos "voluntários saudáveis" (ou seja, homens em que a disfunção erétil não foi diagnosticada) foram incluídos unicamente durante a fase de avaliação da tolerância ao sildenafil (fármacocinética), momento em que a avaliação do melhoramento das ereçôes não fazia parte do protocolo. ${ }^{6}$ Posteriormente, apenas os homens com disfunção erétil diagnosticada participaram dos ensaios da eficiência.

Inicialmente, avaliou-se um grupo de 12 homens que tinham disfunção erétil há pelo menos seis meses, com "ausência de uma causa orgânica". A partir da administração de uma "estimulação sexual visual" com duração de duas horas (revistas e vídeos eróticos), 30 minutos após a administração do produto: “a eficácia do medicamento sobre a atividade erétil do pênis foi avaliada através da medida da rigidez peniana na base do pênis" (BOOLELL et al., 1989, p. 49).

O estudo coloca em evidência a melhoria da rigidez das ereções na presença de um estímulo sexual visual. A possibilidade de que a melhoria da ereção obtida com o tratamento permita o restabelecimento da penetração genital na presença de um "estímulo fisiológico", ou seja, uma mulher, não é mais que uma hipótese...

A avaliação da eficácia do tratamento diz respeito, pois, nesta fase do estudo, ao restabelecimento de uma "função erétil normal" em homens com disfunção erétil (haviam somente avaliado a eficácia do produto) e não à restauração da atividade sexual em geral. Além disso, a descrição do mecanismo de ação do sildenafil pode sugerir que a eficácia vai além desses homens: "O mecanismo de ação sugere que o sildenafil aumenta ou induz ereções, na presença de estimulação sexual, mas ele não irá produzir uma ereção na ausência de um estímulo fisiológico ou sexual." (BOOLELL et al., 1989, p. 52). Para que a avaliação da eficácia do sildenafil fosse realizada em meio natural, faltava ainda um questionário de avaliação a ser preenchido por homens voluntários.

\section{Questionário de avaliação: a construção do padrão da função sexual masculina}

Em 1997, o International Index of Erectile Function (IIEF) foi elaborado com o apoio da empresa Pfizer, que comercializa o Viagra (ROSEN et al., 1997), apesar de dezenas de questionários para avaliar a atividade sexual e disfunções sexuais já 
terem sido colocados anteriormente no mercado (DAVIS et al., 1998). O novo questionário, segundo seus idealizadores, tinha como principal objetivo resolver as dificuldades para estabelecer o diagnóstico e avaliar os resultados dos ensaios terapêuticos de novos tratamentos para a impotência: "Nenhum dos instrumentos já existentes demonstrou sua validade seletiva nem sensibilidade suficiente para avaliar os resultados dos tratamentos em ensaios clínicos multinacionais." (ROSEN et al., 1997, p. 823). O IIEF é um questionário que inclui 15 questões, concebido para avaliar a função erétil, "fácil de usar em ensaios e contextos clínicos." Propõe uma avaliação objetiva da função erétil, incluindo duas perguntas sobre o grau de satisfação na vida sexual e de relacionamento com a parceira.

Dois meses após a aprovação do Viagra pela Food and Drug Administration (FDA), o primeiro ensaio multicêntrico da eficácia do Viagra foi publicado (GOLDSTEIN et al., 1998), com o apoio da empresa farmacêutica Pfizer, produtora do remédio. Esse ensaio destaca a eficácia do medicamento e sua boa tolerância pelos indivíduos em "situação natural". As condiçôes para a inclusão no estudo foram os seguintes:

Em ambos os ensaios, foi estudado um total de 861 homens com idade 18 anos ou mais, com diagnóstico clínico de disfunção erétil de pelo menos seis meses, em 37 centros nos Estados Unidos. Todo homem deveria estar em uma relação estável com parceiro do sexo feminino, que tivesse começado pelo menos seis meses antes.

Os homossexuais e os homens que não vivem com companheira não foram incluídos no teste.

Os resultados evidenciam que a eficácia do medicamento não varia em função da etiologia da desordem (orgânica ou psicogênica). A droga é, por conseguinte, eficaz para todas as formas de "disfunção erétil", qualquer que seja a etiologia. Isto leva os autores a afirmarem que "na maioria dos homens, a disfunção erétil é um problema multifatorial” (GOLDSTEIN, et al., 1998, p. 1.402) e a ausência de um tipo de etiologia não significa necessariamente que a outra é a predominante.

A utilização do IIEF permite aos autores considerar que "o sildenafil melhora a função sexual de homens com disfunção erétil.” (GOLDSTEIN, et al., 1998, p. 1.401). Eles têm um grande cuidado ao afirmar que "o sildenafil supostamente restabelece a resposta erétil natural a uma estimulação sexual e não gera ereções na ausência de tais estímulos." (GOLDSTEIN, et al., 1998, p. 1.398). O sildenafil se diferencia, assim, de outros tratamentos farmacológicos disponíveis (incluindo 
a papaverina), que provocam ereções sem qualquer estimulação sexual. Mas, o que é mais importante, dada a facilidade de uso do Viagra (por via oral) e, para enfrentar as críticas que poderiam ser levantadas pelos meios de comunicação, afirmam com veemência que não se trata de um afrodisíaco. ${ }^{7}$ Sua eficácia não foi testada em homens que não têm disfunção erétil e que poderiam querer aumentar a performance sexual. As parceiras do sexo feminino foram entrevistadas, a fim de verificar a eficácia do tratamento, mas "apenas $25 \%$ das parceiras completaram o questionário opcional” (p. 1.402). Das qualidades do sildenafil, os autores observam que ele permite uma "administração discreta" no que diz respeito à parceira. O deslizamento normativo fica mais preciso: considerando que os primeiros ensaios avaliaram a eficácia da restauração e a melhoria do funcionamento erétil, o grande ensaio clínico aborda toda a "função sexual", propõe uma avaliação da satisfação e tenta levar em consideração as parceiras do sexo feminino, ao mesmo tempo em que pode ser usado na ausência de tais informações. $O$ tratamento farmacológico da "disfunção erétil” aparece implicitamente como um tratamento para a atividade sexual.

\section{A política científica e médica}

A legitimidade da medicalização da impotência é apoiada por uma intensa atividade organizacional. $\mathrm{O}$ processo de legitimação será composto principalmente pela institucionalização de uma comunidade científica em torno da impotência masculina e uma divulgação internacional das ideias de urologistas, em direção aos profissionais do mundo médico e sexual. Há três momentos-chave para se fixar.

\section{Criação de sociedades científicas}

Em 1982, a International Society for Impotence Research (ISIR) é criada com o objetivo de promover a pesquisa e o intercâmbio de conhecimento da entidade clínica: impotência, entre a comunidade científica internacional. A orientação principal da ISIR visa aos estudos científicos fundamentais da ereção, os defeitos no mecanismo erétil e os aspectos clínicos relacionados com o diagnóstico e o tratamento da disfunção erétil.

Os objetivos da ISIR são: estabelecer uma sociedade científica que irá promover critérios mais elevados para a prática, a formação e a pesquisa no domínio da impotência, para benefício do público; promover publicações e incentivar as 
contribuições para a literatura médica e científica; não participar de qualquer atividade motivada pelo lucro; e assegurar que as atividades da sociedade não são de natureza política (ISIR, website). Desde sua criação, a ISIR organiza regularmente as conferências internacionais sobre a impotência. A International Journal of Impotence Research, publicação oficial da ISIR, foi criada em 1989. Seu objetivo científico é "concentrado nos interesses sobre a função normal e patológica de um simples órgão (grifo nosso)". Muito antes do enorme empenho da indústria farmacêutica, a criação desta sociedade se inscreve no ideal científico mais tradicional. Seus fundadores afirmam envolver-se no trabalho em prol da pesquisa e na luta contra os tabus que se opõem ao conhecimento, a serviço do bem público.

A criação da revista permite, assim, a difusão das ideias dessa comunidade no mundo médico e científico. Note-se que o ISIR adotou, em 2000, o nome de International Society for Sexual and Impotence Research (ISSIR), refletindo uma estratégia de abertura a todos os aspectos da sexualidade e em particular a sexualidade feminina, reforçando a alteração (tratamento da "disfunção erétil" versus o restabelecimento da atividade sexual global). No entanto, a principal sociedade científica de estudos da ereção ainda não substituiu o termo "impotência" por "disfunção erétil". Finalmente, a referência ao "simples órgão" foi abandonada em 2004, com a criação da International Society for Sexual Medicine (ISSM), no Congresso Internacional de Buenos Aires. A medicalização da impotência masculina foi um novo passo no sentido da medicalização da sexualidade como um todo.

\section{Conferência de consenso: o apoio de organismos públicos oficiais}

A conferência de consenso organizada pelo National Institute of Health (NIH), em 7, 8 e 9 de dezembro de 1992, marcou o recurso a empresários médicocientíficos no campo da impotência, no que diz respeito às instituições públicas de legitimação da ciência e da medicina.

As regras de funcionamento das conferências de consenso e de desenvolvimento do NIH estipulam que

as comunicações oficiais do NIH são preparadas por um grupo de especialistas nãomilitante, não vinculados à administração federal, e são baseadas em: (1) apresentações de pesquisadores que trabalham no domínio que é objeto da solicitação do consenso, durante uma reunião pública de dois dias; (2) perguntas e respostas 
dos participantes nos debates; (3) deliberações a portas fechadas do grupo de especialistas. O comunicado é um relatório independente do grupo de expertos e não uma declaração política do NIH, nem do governo federal. (NIH, 1992).

A comunicação oficial do NIH incorpora as principais ideias elaboradas pelo "Grupo de Boston". Essas ideias, discutidas e validadas por médicos especialistas de diversas origens, estão começando a sair do pequeno círculo do "Grupo de Boston" e da International Society of Impotence Research. Desde 1992, a comunidade científica e médica dos Estados Unidos reconhece a validade destas novas ideias, propõe o desenvolvimento da medicalização da impotência e lhes dá certa legitimidade. ${ }^{8} \mathrm{O}$ documento do NIH, que ostenta o título Impotência, apesar de defender a substituição do termo por "disfunção erétil”, é amplamente citado como fonte de legitimação por urologistas e pesquisadores que trabalham na área.

\section{Apoio oficial da indústria e abertura aos médicos}

Em 1999, uma "Consulta Internacional sobre disfunção erétil” foi realizada em Paris. Esta consulta, sob direção da OMS e da Sociedade Internacional de Urologia, foi organizada por Saad Khoury, um urologista do Hospital da Pitié-Salpétrière, sob a presidência de Alain Jardim (Professor de Urologia e Chefe do serviço de Urologia no Hospital de Bicêtre). O grupo francês de urologistas (incluindo François Giuliano, professor $^{9}$ de terapêutica e principal pesquisador dos ensaios sobre o Viagra e de outras moléculas na França) visava a equilibrar a influência dos urologistas americanos, dando uma dimensão internacional às deliberações e procurando colocar em foco as ideias dos urologistas europeus. ${ }^{10} \mathrm{~A}$ indústria farmacêutica apoiou esta conferência organizando simpósios satélites sobre diferentes moléculas em teste e financiando o deslocamento e a estadia da maioria dos congressistas. As recomendações da comissão científica internacional da conferência estabeleceram que "quando forem indicados, os tratamentos por via oral serão provavelmente o tratamento de primeira linha para a maioria dos pacientes, devido a seus potenciais benefícios e sua natureza não invasiva" (JARDIN et al., 2000). Esta conferência marca o reforço da internacionalização da medicalização da impotência e a aliança entre os urologistas e a indústria farmacêutica. O apoio da OMS reforça a legitimidade desse processo. 
A realização do $15^{\circ}$ Congresso da Associação Mundial de Sexologia (WAS World Association of Sexology), que reuniu cerca de 2.500 participantes de todo o mundo em Paris, em junho de 2001, marcou o ponto culminante da entrada em vigor da indústria farmacêutica e dos urologistas no mundo da sexologia. A WAS é tradicionalmente um local de intercâmbios que equilibra as comunicações dos sexologistas médicos e não-médicos, que aborda as questōes da educação sexual e da prevenção e que defende um conceito global de saúde sexual (GIAMI, 2002). A conferência de Paris concedeu os melhores horários e as maiores salas (beneficiando a tradução simultânea para o francês, inglês e espanhol) às apresentações dedicadas ao tratamento das perturbaçôes sexuais, em detrimento das apresentaçôes de prevenção e educação sexual, que habitualmente costumam atrair a maioria dos participantes da América Latina e da Ásia.

$\mathrm{Na}$ França, a divulgação das ideias e das recomendações clínicas foram objeto de aliança entre a indústria farmacêutica e as sociedades médicas. Henri Navratil, professor de urologia em Montpellier, fundador da Sociedade de Andrologia de Língua Francesa (SALF) estruturou a reunificação da SALF, da Associação Francesa de Urologia (AFU) e da Associação de Intercâmbio entre Hospitais Universitários de Sexologia (AIHUS) para organizar a formação de médicos no âmbito do programa "Objetivo Disfunçōes Eréteis", lançado em julho de 1998, em Paris, sob a direção da Pfizer. Os principais membros dessas sociedades constituíram o comitê científico de um importante programa de formação continuada destinada aos médicos especialistas e aos médicos sexologistas, em primeira instância e, em seguida, aos médicos generalistas. Muitos médicos especialistas e generalistas desfrutaram tardes de formação organizadas antes da comercialização do Viagra. Encontramos, no caso do Viagra, a situação que prevalece para as drogas psicotrópicas, em que a indústria farmacêutica controla de modo quase exclusivo a informação e a formação dos médicos, na ausência de formação acadêmica sobre temas relacionados com a função sexual (ZARIFIAN, 1996).

Inicialmente, a legitimação da concepção medicalizada da impotência tomou o caminho da institucionalização das redes de pesquisas, com a criação de sociedades e de revistas científicas. Em seguida, o grupo de empresários urologistas solicitou às instâncias médico-científicas oficiais americanas que dessem sua aprovação ao programa científico e emitissem recomendações em se tratando de diagnóstico e tratamento. É neste momento, da preparação para o lançamento do medicamento, 
que as relações entre os pesquisadores e a indústria farmacêutica se fortalecem e se tornam explícitas. Até então, a fabricação das moléculas permanecia no seio da indústria, o estabelecimento dos testes de eficácia e suas avaliações requerem o know-how de especialistas da impotência. Por isso, é razoável dizer que os medicamentos dos transtornos sexuais são uma "invenção da indústria farmacêutica" (MOYNIHAN, 2003): eles resultam de um intenso apoio político e financeiro da indústria farmacêutica aos pesquisadores, há muito tempo envolvidos nas pesquisas da área. A partir desse momento, os interesses da indústria e dos pesquisadores convergem para um comércio comum. Posteriormente, os pesquisadores trabalham com o apoio da indústria farmacêutica. Eles se beneficiam do apoio para a divulgação de ideias, desenvolvendo recomendaçôes práticas (diagnóstico e terapêutica) e na formação de profissionais colocados na primeira linha da prescrição dos tratamentos. $\mathrm{O}$ termo "disfunção erétil" impôs-se em situações que são controladas pela indústria farmacêutica, enquanto que a expressão "impotência" continua a circular no mundo médico.

\section{Em direção à desmedicalização?}

A medicalização da impotência masculina contém as origens da desmedicalização dos tratamentos farmacológicos da impotência masculina e, de uma forma mais geral, de todos os problemas relacionados com a sexualidade. A existência de medicamentos "eficazes e bem tolerados" e de simples utilização pode ajudar a resolver os problemas comuns da vida quotidiana, colocando efetivamente em questão a necessidade de uma prescrição médica.

O principal argumento apresentado pelos médicos e pela indústria farmacêutica para a necessidade de prescrição é que existem riscos e efeitos secundários associados às contraindicações do Viagra. Isso nos sensibiliza ao tema "morreu de Viagra", que havia surgido por ocasião do lançamento do medicamento, na literatura especializada e nos meios de comunicação. O Viagra, "Pharmakon" moderno, apareceu como um remédio e como um veneno. O controle médico e a prescrição destinavam-se a proteger indivíduos em risco potencial e, talvez, o laboratório contra um eventual processo. A questão dos graves riscos associados ao consumo de Viagra, entretanto, desapareceu da imprensa médica e da imprensa em geral. 
No simpósio organizado pela Assembleia Nacional Francesa ${ }^{11}$ em 25 de abril de 2001, o professor Joel Ménard, antigo Diretor-Geral da Saúde, ${ }^{12}$ especialista em hipertensão mundialmente reconhecido, preconizou, a título pessoal, a venda livre do Viagra (over the counter). Segundo ele, a sociedade e os seguros de saúde não têm por função normalizar a atividade sexual da população através da definição das regras de acesso ao consumo de um produto desse tipo, especialmente quando há apenas riscos menores.

Esta posição, contudo, refere-se a uma situação real. O Viagra é acessível em muitos países, após a obtenção da sua aprovação, através da autoprescrição (como no Brasil ou na Tailândia, por exemplo) e através da Internet. Ele já é utilizado como droga recreativa (ALDRIDGE; MEASHAM, 1999) e, muitas vezes, associado a substâncias psicoativas ilícitas. Algumas organizações gay têm recomendado não consumir o Viagra com poppers, um potente vasodilatador derivado do nitratoamylo, fortemente contraindicado na interação com o sildenafil.

As principais reações médicas ao fornecimento do Viagra na Internet manifestaram preocupação em relação ao desenvolvimento dessa situação, que não leva em conta os riscos potenciais. O desenvolvimento das prescrições on line escapa, como sabemos, ao controle dos médicos. A facilidade da utilização do medicamento, a inexistência de riscos associados e seu alto custo não coberto pelo seguro-saúde prefiguram sua utilização como automedicação, sob a forma de afrodisíaco ou, mais especificamente, de medicamento que ajuda a gestão racional dos atos da vida quotidiana. Os representantes dos médicos permanecem recomendando maior controle do Viagra através de prescrições (ARMSTRONG; SCHWARTZ; ASCH, 1999).

\section{Conclusão}

A medicalização atual da impotência masculina é baseada num processo que começou no início dos anos 80 , com as novas descobertas científicas no campo da biomedicina (fisiologia, endocrinologia, neurologia) e da descoberta dos efeitos da papaverina sobre a ereção. Um grupo de médicos empresários urologistas assumiu, então, o compromisso de reconceitualizar a impotência masculina no campo da medicina organicista, abandonando os conceitos psicológicos que prevaleciam nas décadas anteriores, distanciando-se da abordagem cirúrgica, que era central na urologia de então. Os mesmos urologistas ocupavam o domínio da epidemiologia e estabeleceram novos dados sobre a prevalência da impotência. $O$ desenvolvimento 
da droga sildenafil, pelo laboratório Pfizer, que obteve sua patente em 1993, abriu oportunidades e possibilidades para o financiamento da pesquisa. Pesquisa esta que levou ao desenvolvimento de um instrumento para avaliar o impacto do tratamento e ajudou no diagnóstico e na realização de ensaios clínicos, destacando a segurança e a eficácia do medicamento.

Enquanto o trabalho de reconceitualização da impotência masculina e a investigação epidemiológica foram financiados por fundos públicos e universitários, a elaboração do questionário e os ensaios clínicos marcaram a entrada da indústria farmacêutica no campo da impotência e sua associação com pesquisadores e médicos que haviam começado a trabalhar na impotência há muitos anos. A partir do momento em que a indústria produz um medicamento, assistimos à confluência entre os interesses da indústria e dos médicos e pesquisadores.

"Disfunção erétil" é diferente de impotência? Em primeiro lugar, deve-se salientar que a maioria dos autores, em função das circunstâncias, emprega alternadamente um ou outro termo. O termo "impotência" é agora considerado como "pejorativo" e "inapropriado", na medida em que ele pode abranger a totalidade do ciclo de resposta sexual do homem, enquanto que o termo "disfunção erétil” considera que o mecanismo de ereção é o único alvo de tratamento. A impotência, como patologia, diz respeito às formas graves, ou seja, "primárias". Os episódios de impotência secundária, transitória ou situacional, eram considerados como "o limite normal do funcionamento sexual" (KAPLAN, 1974) pelos médicos mais renomados dos anos 1970. A concepção da disfunção erétil contribuiu para as inovações conceituais no estabelecimento dos graus de gravidade (da mais leve para a mais grave) e incluiu todos os homens que têm um baixo nível de disfunção neste campo de patologia. A causa da impotência foi considerada principalmente psicogênica, enquanto a disfunção erétil é considerada sobretudo orgânica. Portanto, a disfunção erétil se distingue da impotência por uma ênfase e uma focalização no campo da organicidade e por uma extensão da prevalência da ocorrência em homens, incluindo as formas menos graves.

No final deste percurso, que começou no início dos anos 80, rastreou-se a evolução das ideias médicas, científicas e sociais em relação à impotência masculina e sua transformação gradual, apesar de não totalmente alcançada, em "disfunção erétil”. Se cientistas e médicos (principalmente urologistas) têm desempenhado papel fundamental nessa evolução conceitual, a indústria farmacêutica tem moldado 
muito rapidamente um novo medicamento e novos tratamentos para esta nova entidade clínica, contribuindo para a propagação destas ideias e para sua transformação. Ao escolher designar toda esta situação como um "tratamento eficaz e bem tolerado para uma doença devidamente repertoriada", a indústria foi confrontada pelas instâncias reguladores da distribuição dos medicamentos, o que contribuiu um pouco mais para a evolução das ideias.

O desenvolvimento de um medicamento para "disfunção erétil" deve ser entendido como um fenômeno cultural em diferentes planos. Ele é a renovação do discurso público sobre a sexualidade, que no final dos "anos Aids" tornou-se novamente portador de certo otimismo. Entre várias perspectivas possíveis, a indústria farmacêutica optou por "acondicionar" o Viagra como um medicamento "eficaz e bem tolerado" no campo da urologia, podendo ser obtido unicamente por prescrição médica para o tratamento de uma doença, visando restaurar uma "atividade sexual natural e normal" no contexto do casal heterossexual. Os discursos nos meios de comunicação deram uma configuração diferente para o produto, designando-o como um afrodisíaco que pode ser utilizado para uma atividade sexual com fins recreativos. Uma terceira maneira é aberta, que consiste em considerar esse tipo de medicamento como uma "droga de conforto", visando a melhorar a qualidade de vida e o gerenciamento dos comportamentos diários. Estas duas últimas perspectivas constituem um reposicionamento da função da medicina, que, além do tratamento das doenças, contribuiria para a Saúde (dentro da definição da OMS, como uma forma de "bem-estar físico, mental e social"). Assim, paradoxalmente, a medicalização da impotência masculina abre a porta para a desmedicalização da sexualidade, excluindo os médicos, e colocando o desenvolvimento de normas de saúde e de sexualidade sob o controle da indústria farmacêutica.

\section{Referências}

ACTON, W. The functions and disorders of the reproductive organs in childhood, youth, adult age, and advanced life considered in their physiological, social and moral response. Philadelphia: Lindsay \& Blakiston, 1865.

ALDRIDGE, J.; MEASHAM, F. Sildenafil (Viagra) is used as a recreational drug in England. British Medical Journal, v. 318, p. 669, 1999.

ARMSTRONG, K.; SCHWARTZ, J.; ASCH, D. Direct sale of Sildénafil (Viagra) to consumers over the Internet. The New England Journal of Medicine, v. 341, p. 1.389-1.392, 1999. 
BEARD, G. M. Sexual neurasthenia [nervous exhaustion]: its hygiene, causes, symptoms, and treatment, with chapter on diet for the nervous. New York: E.B. Treat, 1884.

BELLIOL. De l'impuissance ou perte de virilité. Paris: Chez l'auteur, 1832.

BOOLELL, M.; ALLEN, M. J.; BALLARD, S. A. et al. Sildenafil: an orally active type 5 cyclic GMP specific phosphodiesterase inhibitor for the treatment of penile erectile dysfunction. Int J Impot Res, v. 8, n. 2, p. 47-52, 1996.

CONRAD, P. The medicalization of society. Baltimore: The Johns Hopkins University Press, 2007.

CONRAD, P.; SCHNEIDER, J. Deviance and medicalization : from badness to sickness. SaintLouis: The C.V. Mosby Company, 2007.

DARMON, P. Le tribunal de l'impuissance. Paris: Seuil, 1979.

DAVIS, C.; YARBER, W.; BAUSERMAN, R. et al. Handbook of Sexuality-Related Measures. Sage: London, 1998.

EHRENBERG, A. La fatigue d'être soi. Dépression et Société. Paris: Odile Jacob, 1998.

FASSIN, D. Les politiques de la médicalisation. In: AÏACH, P.; DELANOE, D. (Ed.). L’ère de la médicalisation. Paris: Anthropos, 1998. p. 1-13.

FELDMAN, H.; GOLDSTEIN, I.; HATZICHRISTOU, D. et al. Impotence and its medical and psychosocial correlates : results of the Massachussets Male Aging Study. The Journal of Urology, $\mathrm{n}$. 151, p. 54-61, 1994.

FOUCAULT, M. Histoire de la sexualité. Tome 1, La volonté de savoir. Paris: Gallimard, 1976.

FURCHGOTT, R.; IGNARRO, L. J. Proceedings of the National Academy of Sciences, n. 84, p. 9.265-9.268, 1987.

GARCIA-REBOLL, L.; MULHALL, J. P.; GOLDSTEIN, I. Drugs for the treatment of impotence. Drugs Aging, v. 11, n. 2, p. 140-151, Aug. 1997.

GIAMI, A. A medicalização da sexualidade. Foucault e Lantéri-Laura: história da medicina ou história da sexualidade? PHYSIS: Rev. Saúde Coletiva, Rio de Janeiro, v. 15, n. 2, p. 259-284, 2005.

. Cent ans d'hétérosexualité. Actes de la Recherche en Sciences Sociales, n. 128, p. 38-45, 1999.

. Médicalisation de la société et médicalisation de la sexualité. In : JARDIN, A.; QUENEAU,

P.; GIULIANO, F. (Ed.). Progrès thérapeutiques : la médicalisation de la sexualité en question. Paris: John Libbey Eurotext. 2000a. p. 121-130.

- Permanência das representações do gênero em sexologia: as inovações científica e médica comprometidas pelos estereótipos de gênero. Physis: Rev. Saúde Coletiva, Rio de Janeiro, v. 17, n. 2 , p. 301-320, 2007.

Sexual health: the emergence, development and diversity of a concept. Annual Review of Sex Research, v. XIII, p. 1-35, 2002. 
GIAMI, A. Socioepidemiologia da impotência masculina. Revista Terapia Sexual, v. III, n. 2, p. 133, $2000 \mathrm{~b}$.

GIAMI, A.; PIETRI, L. Les traitements de l'impuissance. Paris: La Documentation Française, 1999. GOLDSTEIN, I.; LUE, T.; PADMA-NATHAN et al. Oral sildenafil in the treatment of erectile dysfunction The New England Journal of Medecine, v. 338, n. 20, p. 1.397-1.404, 1998.

HITT, J. The second sexual revolution. The New York Times Magazine, 20 février, 2000.

INTERNATIONAL SOCIETY FOR IMPOTENCE RESEARCH. By laws. Disponível em: http://www.apsir.org/html/bylaws_isir.htm Acesso em: 20 set. 2008.

JARDIN, A.; QUENEAU, P.; GIULIANO, F. (Ed.). Progrès thérapeutiques: la médicalisation de la sexualité en question. Paris: John Libbey, 2000.

JARDIN, A.; WAGNER, G.; KHOURY, S. et al. Erectile Dysfunction: 1st international Consultation on Erectile Dysfunction. Paris: Comité Scientifique International, 2000.

KAPLAN, H. S. The New Sex Therapy. New York: Times Books, 1974.

KRANE, R.; GOLDSTEIN, I.; SAENZ DE TEJADA, I. Impotence. The New England Journal of Medicine, v. 321, n. 24, p. 1.648-1.659, 1989.

KRANE, R.; SIROKY, M.; GOLDSTEIN, I. Male sexual dysfunction. Boston: Little, Brown \& Company, 1983.

LEWIS, R.; WAGNER, G. History of the International Society of Sexual Medicine: the beginnings Journal of Sexual Medicine, n. 5, p. 740-745, 2008.

MASTERS, W.; JOHNSON V. Les mésententes sexuelles et leur traitement. Paris: Robert Laffont, 1971. p. 131-147.

MOYNIHAN, R. The making of a disease: female sexual dysfunction. British Medical Journal, v. 326, p. 45-47, 2003.

NATIONAL INSTITUTES OF HEALTH. Impotence. NIH Consens Statement Online, v. 10, n. 4, p. 1-31, 1992. Disponível em: http://www.ncbi.nlm.nih.gov/books/ bv.fcgi?rid=hstat4.chapter.11491. Acesso em: set. 2008.

RAJFER, J.; ARONSON, W. J.; BUSH, P. A. et al. Nitric oxide as a mediator of relaxation of the corpus cavernosum in response to nonadrenergic, noncholinergic neurotransmission. The New England Journal of Medicine, v. 326, p. 90-94, 1992.

ROSEN, R. C.; RILEY, A.; WAGNER, G. et al. The International Index of Erectile Function. Urology, v. 49, p. 822-830, 1997.

ROUBAUD, F. Traité de l'impuissance et de la stérilité chez l'homme et chez la femme. Paris: J.-B. Baillière, 1855 . 
SEAGRAVES, R. T. Pharmacological era in the treatment of sexual disorders. Journal of Sex and Marital Therapy, n. 24, p. 67-68, 1998.

SHABSIGH, R.; ALEXANDRE, L.; NIELSEN, H. et al. Economical aspects of erectile dysfunction. In: JARDIN, A. et al. Erectile Dysfunction: 1st international Consultation on Erectile Dysfunction. Paris: Comité Scientifique International, 2000. p. 55-64.

SIMONS, J.; CAREY, M. Prevalence of sexual dysfunctions: results from a decade of research. Archives of Sexual Behavior, v. 30, n. 2, p. 177-219, 2001.

SPECTOR, I. P.; CAREY, M. P. Incidence and prevalence of the sexual dysfunctions: a critical review of the litterature. Archives of Sexual Behavior, v.19, p. 389-408, 1990.

TIEFER, L. The medicalization of sexuality. Annual Review of Sex Research, n. 7, p. 252-282, 1996. TRIMMER, E. Sexologie clinique. Paris: Masson, 1981.

VIRAG, R. Intracavernous injection of papaverine for erectile failure. Lancet, v. 2, p. 938, 1982. ZARIFIAN, E. Le Prix du bien-être. Paris: Odile Jacob, 1996.

ZUCKER, K. From the editor's desk: receiving the torch in the era of sexology renaissance. Archives of Sexual Behavior, v. 31, n. 1, p. 1-6, 2002.

\section{Notas}

${ }^{1}$ Este artigo foi baseado numa análise da literatura científica, médica e de saúde pública sobre o tratamento da impotência masculina, na leitura da imprensa francesa e internacional, na participação em vários congressos médicos, na realização de um estudo sociológico sobre a profissão de sexólogo e em entrevistas e conversas informais. Além disso, é baseado na experiência pessoal, a partir da participação em um grupo de trabalho sobre o tratamento da impotência, estabelecidos pelo Diretor Geral da Saúde da França em junho de 1998.

${ }^{2}$ Nesta mesma época, quando a relação sexual começou a ser considerada uma base para a comunicação, J. Lacan escreveu que "a relação sexual não existe".

${ }^{3}$ Os trabalhos da segunda fase de Masters e Johnson, no final dos anos 70, estabeleceram o princípio da equivalência generalizada de todas as práticas sexuais para atingir o orgasmo, levando em conta as pessoas que não vivem como um casal heterossexual. Sobre esse ponto, ver Giami (1999).

${ }^{4}$ A equipe de pesquisadores (Robert F. Furchgott, Louis Ignarro e Ferid Murad) que descobriu o NO2 (óxido nítrico) ganhou o Prêmio Nobel da Medicina em 1998, ano de colocação no mercado do Viagra. Além disso, o NO2 foi selecionado como a "molécula do ano" em 1992 pela revista Science. Um romance de ficção científica ostenta o título de "NO2" (C. DJERASSI, University of Georgia Press, 1998). Isso pode ser lido sob forma de ficção: as principais fases da construção sócio-científica de um produto similar ao Viagra, assim como os detalhes das ligações entre as universidades, as indústrias de biotecnologia, as agências reguladoras (FDA) e a bolsa de valores. 
${ }^{5}$ Sobre este ponto, ver o debate suscitado no British Medical Journal no momento da publicação de um artigo de Moynihan (2003), e Giami (2007).

${ }^{6}$ Um responsável médico dos laboratórios Pfizer-France nos afirmou, sob anonimato, que a nãoinclusão de "voluntários saudáveis" nos testes de eficácia, isto é, homem sem disfunção erétil, resultou de uma estratégia muito clara por parte do laboratório. Ele advertiu que de modo algum poderia sugerir que o Viagra fosse utilizado como um afrodisíaco, mas sim determinar sua eficácia no tratamento de uma doença (comunicação pessoal, julho 1998).

${ }^{7}$ O Laboratório Pfizer tem colocado a gestão de Viagra na sua divisão de "Urologia".

${ }^{8} \mathrm{O}$ documento do NIH foi objeto de um debate no número do International Journal of Impotence Research (v. 5, n. 4, Décembre 1993). Leonore Tiefer resume em poucas palavras essas questões: "de fato simplificando mal, os urologistas têm gostado deste relatório, enquanto que os sexologistas viram nele lacunas importantes". (TIEFER, op.cit., p. 277).

${ }^{9}$ Maître de conférences no original (N.da R.).

${ }^{10}$ Os urologistas franceses preferem o termo "insuficiência erétil".

${ }^{11}$ Corresponderia, no Brasil, ao Congresso Nacional (N. da R.).

${ }^{12}$ Cargo que, no Brasil, corresponde ao de Ministro da Saúde (N.da R.). 
From impotence to erectile dysfunction: a journey through the medicalization of sexuality

This paper delineates the history of the recent transformation of the concept of impotence - from a psycho-social disorder to a disease with an organic etiology. Then it shows how male impotency, which globally affected the entire sexual response cycle, even acted upon self-image and the representation of the couple - progressively became a disorder as the failure of a well controlled organ liable to undergo a single medicinal treatment. This process is analyzed from the sequential model of medicalization, making the interference of the several actors implied (scientists, practitioners, industrialists, politicians, businessmen) easier to understand. This sheds light on the way scientific discoveries are selected and developed according to their industrial potential, then applied to clinical research; how clinical entities are reconceptualized and measured through epidemiologic studies among the general population, how clinical trials are conducted and how they lead to the creation and validation of a drug in public health settings. Next, we observe how public health actors and politicians are involved with giving this new problem legitimacy. Eventually, we evaluate the germs of de-medicalization, caused by the non-medical uses of the drug within the context of self-prescription which is currently developed on the Internet.

Key words: medicalization; erectile dysfunction; sexuality. 